\title{
The chromogranin A-derived peptides catestatin and vasostatin in dogs with myxomatous mitral valve disease
}

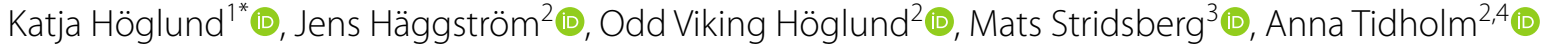 \\ and Ingrid Ljungvall ${ }^{2}$
}

\begin{abstract}
Background: The protein chromogranin A ( $\mathrm{CgA})$ is stored and co-released with catecholamines from the stimulated adrenal glands. Increased plasma concentrations of $\mathrm{CgA}$ have been shown in people with heart disease. The aim of the study was to investigate whether plasma concentrations of the CgA-derived biologically active peptides catestatin and vasostatin were associated with the severity of myxomatous mitral valve disease (MMVD) in dogs and to assess potential associations between these blood variables and dog characteristics, echocardiographic variables, heart rate (HR), blood pressure (BP) and plasma N-terminal-proBNP (NT-proBNP) concentration. Sixty-seven privately owned dogs with or without MMVD were included. The dogs underwent physical examination, blood pressure measurement, blood sample collection, and echocardiographic examination. Plasma concentrations of catestatin and vasostatin were analyzed using radioimmunoassay.
\end{abstract}

Results: Catestatin concentration decreased with increasing left atrial and ventricular size $\left(R^{2} \leq 0.09, P \leq 0.019\right)$, and increased with increasing systolic and diastolic blood pressures $\left(R^{2} \leq 0.08, P \leq 0.038\right)$. Regression analyses showed no significant associations for vasostatin. No differences in plasma concentrations of catestatin or vasostatin were found between the disease severity groups used in the study.

Conclusions: In the present dog population, the catestatin concentration showed weak negative associations with left atrial and ventricular sizes, both of which are known to increase with increasing severity of MMVD. Furthermore, the catestatin concentration showed weak positive associations with blood pressure.

Keywords: Canine, Catestatin, Heart, Sympathetic nervous system, Vasostatin

\section{Background}

Chromogranin A ( $\mathrm{CgA})$ is an acidic, soluble secretory protein, belonging to the granin family. The protein has a widespread distribution in neuroendocrine and endocrine tissues as well as in the central and peripheral nervous systems, and is also abundant in the chromaffin

\footnotetext{
*Correspondence: Katja.Hoglund@slu.se

${ }^{1}$ Department of Anatomy, Physiology and Biochemistry, Faculty

of Veterinary Medicine and Animal Science, Swedish University of Agricultural Sciences, 75007 Uppsala, Sweden

Full list of author information is available at the end of the article
}

cells of the adrenal medulla. Chromogranin A co-exists in secretory granules with catecholamines, with which it is co-released during exocytosis [1-3]. Chromogranin $\mathrm{A}$ is also produced in the human myocardium and has been found co-localized with B-type natriuretic peptide (BNP) in the myocardium of people with heart disease [4]. Chromogranin A is a precursor of several biologically active peptides, including catestatin and vasostatin [5], which modulate cardiac hemodynamics during adrenergic stimulation and seem to protect the cardiovascular system against excessive beta-adrenergic stimulation [6].

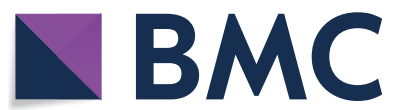

(c) The Author(s) 2020. This article is licensed under a Creative Commons Attribution 4.0 International License, which permits use, sharing, adaptation, distribution and reproduction in any medium or format, as long as you give appropriate credit to the original author(s) and the source, provide a link to the Creative Commons licence, and indicate if changes were made. The images or other third party material in this article are included in the article's Creative Commons licence, unless indicated otherwise in a credit line to the material. If material is not included in the article's Creative Commons licence and your intended use is not permitted by statutory regulation or exceeds the permitted use, you will need to obtain permission directly from the copyright holder. To view a copy of this licence, visit http://creativeco mmons.org/licenses/by/4.0/. The Creative Commons Public Domain Dedication waiver (http://creativecommons.org/publicdomain/ zero/1.0/) applies to the data made available in this article, unless otherwise stated in a credit line to the data. 
In contrast to catecholamines, which degrade rapidly in plasma [7], CgA has a high stability [8] and is considered a useful marker of sympathetic nervous activation [9, 10]. In people, plasma CgA has been shown to increase in situations of pronounced sympathetic stimulation such as in critically ill patients [11]. High plasma CgA concentrations have been found in people with congestive heart failure (CHF) due to coronary artery disease, arterial hypertension, dilated cardiomyopathy (DCM), hypertrophic cardiomyopathy and valvular disease [4, 12-14] and plasma CgA concentration has been shown to increase with increasing severity of different human cardiac diseases [12]. Furthermore, studies in people with acute myocardial infarction have shown increased catestatin concentrations in plasma [15-17] as well as in serum [18], while one study showed decreased serum vasostatin-2 concentrations in patients with chronic heart failure due to previous myocardial infarction, compared to in healthy controls [19].

In dogs, myxomatous mitral valve disease (MMVD) is the most common heart disease [20-22]. The disease is characterized by slow progressive degeneration of the mitral valve apparatus, leading to mitral regurgitation (MR). With progressive degeneration of the valve leaflets, the regurgitation increases, leading to volume overload and subsequent dilation of the left atrium and ventricle, and risk of developing CHF [20,23]. During progression of the disease, neuroendocrine activation takes place [24, 25], and increased plasma norepinephrine concentrations have been found in dogs with DCM and in dogs with advanced MMVD [26, 27].

Plasma concentrations of CgA or derived peptides have not been investigated in dogs with heart disease. A radioimmunoassay (RIA) for measurement of the peptides catestatin and vasostatin, which both have cardiovascular functions [5], has been validated for canine plasma [28]. Hence, the aims of the present study were to investigate whether plasma concentrations of catestatin and vasostatin were associated with severity of MMVD in dogs and to assess potential associations between plasma concentrations of catestatin and vasostatin and dog characteristics, echocardiographic variables, heart rate (HR), blood pressure (BP) and plasma N-terminal-proBNP (NTproBNP) concentration.

\section{Methods}

\section{Animals}

Client-owned dogs were examined at the cardiology unit at the University Teaching Hospital of the Swedish University of Agricultural Sciences in Uppsala, Sweden according to a pre-specified protocol. To be included, dogs had to either have evidence of MMVD or be free from physical or echocardiographic evidence of cardiac disease. Dogs in need of heart failure therapy were allowed into the study. Dogs with congenital heart disease, other acquired cardiovascular disorders or significant organ-related or systemic diseases were excluded.

\section{Examinations}

Dogs underwent physical examination, blood pressure measurement, blood sample collection, and echocardiographic examination, all performed during the same consultation. Blood pressure was indirectly measured using an automated oscillometric device (Vet HDO monitor, $\mathrm{S}+\mathrm{B}$ med Vet $\mathrm{GmbH}$, Babenhausen, Germany). Once reliable consecutive readings were obtained, five consecutive blood pressure recordings were performed and the mean was calculated. Blood was collected by jugular venipuncture into EDTA-tubes; plasma was separated by centrifugation within $30 \mathrm{~min}$ of collection, transferred to plastic cryotubes and stored at $-80{ }^{\circ} \mathrm{C}$ for batched analysis.

Echocardiography, performed by an ultrasonographic unit (iE33, Philips Ultrasound, Bothell, WA, USA), was used to verify the diagnosis of MMVD and to exclude other cardiac diseases. Assessment of mitral valve structures was performed and degree of MR was assessed by color Doppler. The MR was subjectively assessed as the area of regurgitant jet relative to the area of the left atrium [29] with slight modifications [30]. Measurements of the left ventricle (five consecutive cardiac cycles) and left atrial to aortic root (LA/Ao) ratio (three consecutive cardiac cycles) were performed as previously described $[31,32]$. The mean value for each variable was used in the statistical analyses. Diagnostic criteria for MMVD included characteristic 2-dimensional valvular lesions of the mitral valve apparatus (thickened and/or prolapsing mitral valve leaflets) and demonstrated MR by color Doppler [29, 33]. Estimation of MMVD severity was based on obtained LA/Ao ratio and MR jet size, and dogs were classified as follows: Healthy (LA/Ao $<1.5$ and non to minimal MR jet), mild (LA/Ao $\leq 1.5$ and $\mathrm{MR}$ jet $<30 \%$ ), moderate (LA/Ao $<1.8$ and $\mathrm{MR}$ jet $\leq 50 \%$ ), and severe (LA/Ao $\geq 1.8$ and MR jet $>50 \%$ ) MMVD [30, 34, 35]. Values for percent increases of end-diastolic left ventricular internal dimension $\left(\operatorname{LVIDd}_{\text {inc }}\right)$ and end-systolic left ventricular internal dimension $\left(\mathrm{LVIDs}_{\text {inc }}\right)$ were calculated as previously described [30,36].

\section{Analyses of catestatin and vasostatin}

Analyses of plasma catestatin and vasostatin concentrations were performed by RIAs specific for catestatin and vasostatin [37, 38], validated for use in dogs [28]. The coefficient of variation was $3.6 \%$ and $8.8 \%$ for catestatin and vasostatin, respectively. The samples had been thawed and refrozen once before the analyses. 


\section{Statistical analyses}

Statistical analyses were performed using commercially available software (JMP Pro, version 14.0.0, SAS Institute Inc, Cary, NC, USA). Data are presented as medians and interquartile ranges (IQR). A P-value $<0.05$ was considered significant, unless otherwise indicated. The nonparametric Kruskal-Wallis test was used to investigate overall differences between MMVD groups in plasma catestatin and vasostatin concentrations. If a significant difference was detected, pair-wise breed comparisons were performed by Mann-Whitney U-test with Bonferroni adjustment (adjusted $\mathrm{P}<0.008$ ). The same statistical methods were used to assess differences between MMVD groups in all basic variables for dog characteristics, clinical, and echocardiographic data, Table 1.

Potential differences between dogs in CHF and dogs without CHF in plasma catestatin and vasostatin concentrations were evaluated by Kruskal-Wallis test, as was potential sex differences in plasma catestatin and vasostatin concentrations.

Univariable regression analyses were performed to evaluate potential associations between age, body weight, systolic (SBP) and diastolic (DBP) blood pressure, HR, NT-proBNP concentration and echocardiographic variables (LA/Ao, LVIDd inc\%, LVIDs inc\%, fractional shortening (FS)), and plasma catestatin and vasostatin concentrations. To evaluate if potential associations were preserved in dogs not affected by decompensated CHF, the same univariable regression analyses were repeated excluding dogs in decompensated CHF $(n=5)$. For the univariable regression analyses catestatin, vasostatin, LA/ Ao and NT-proBNP concentrations were logarithmically transformed to correct for non-normality.

\section{Results}

Sixty-seven dogs, 38 females and 29 males, with median age 7.7 (IQR 5.9-9.6) years and median body weight 9.6 (IQR 7.7-10.3) kg were included. Summary statistics for the different MMVD severity groups are shown in Table 1. Among the 16 dogs with severe MMVD, five were in decompensated CHF at the time of inclusion, while five dogs had previously been diagnosed with $\mathrm{CHF}$, stabilized by heart failure therapy, and were in compensated $\mathrm{CHF}$ at the time of inclusion. In dogs with decompensated $\mathrm{CHF}$ at sampling, heart failure therapy was initiated. At the time of sampling, the following number of dogs were treated with furosemide $(n=8)$, pimobendan $(\mathrm{n}=4)$, ACE-inhibitor $(\mathrm{n}=3)$, digoxin $(\mathrm{n}=2)$ and spironolactone $(\mathrm{n}=1)$.

Median catestatin concentration in all dogs was 1.13 (IQR 1.00-1.23) nmol/L, with no differences in concentration between MMVD groups. Median vasostatin concentration in all dogs was 0.19 (IQR 0.13-0.30) nmol/L, with no differences in concentration between MMVD groups. Catestatin concentration did not differ between dogs with or without CHF, but was numerically higher

Table 1 Dog characteristics, clinical and echocardiographic data in 67 dogs grouped by severity of myxomatous mitral valve disease (MMVD)

\begin{tabular}{|c|c|c|c|c|}
\hline Group & Healthy & Mild & Moderate & Severe \\
\hline Number & 20 & 23 & 8 & 16 \\
\hline Sex (female/male) & $14 / 6$ & $15 / 8$ & $5 / 3$ & $4 / 12$ \\
\hline Age (years) & $4.9(2.8-6.4)^{\mathrm{a}}$ & $7.2(6.2-10)^{b}$ & $9.1(7.0-10)^{b}$ & $9.2(8.7-11)^{b}$ \\
\hline Body Weight (kg) & $8.8(7.0-10.1)^{a}$ & $9.6(8.0-10.6)^{a}$ & $8.9(7.6-10)^{\mathrm{a}}$ & $10(7.7-12)^{\mathrm{a}}$ \\
\hline $\mathrm{HR}(\mathrm{bpm})$ & $100(93-111)^{\mathrm{a}}$ & $100(92-112)^{\mathrm{a}}$ & $100(100-120)^{\mathrm{ab}}$ & $120(100-150)^{b c}$ \\
\hline $\mathrm{SBP}(\mathrm{mmHg})$ & $134(119-138)^{\mathrm{ab}}$ & $139(132-152)^{\mathrm{a}}$ & $139(127-153)^{\mathrm{ab}}$ & $123(116-134)^{b}$ \\
\hline $\mathrm{DBP}(\mathrm{mmHg})$ & $75(65-80)^{a b}$ & $78(70-86)^{\mathrm{a}}$ & $75(72-80)^{a b}$ & $68(64-75)^{\mathrm{b}}$ \\
\hline $\mathrm{LA} / \mathrm{Ao}$ & $1.2(1.1-1.2)^{\mathrm{a}}$ & $1.3(1.2-1.4)^{b}$ & $1.6(1.5-1.6)^{c}$ & $2.1(2.0-2.6)^{d}$ \\
\hline LVIDd (cm) & $3.0(2.7-3.4)^{\mathrm{a}}$ & $3.4(3.1-3.7)^{a b}$ & $3.5(3.4-3.9)^{b}$ & $4.4(4.1-4.8)^{c}$ \\
\hline $\operatorname{LVIDd}_{\text {inc }}(\%)$ & $4.0(-2.4 \text { to } 15)^{\mathrm{a}}$ & $14(4.5-24)^{a b}$ & $24(16-38)^{b}$ & $45(41-59)^{c}$ \\
\hline LVIDs (cm) & $2.1(1.8-2.5)^{\mathrm{a}}$ & $2.3(2.1-2.7)^{\mathrm{a}}$ & $2.3(2.2-2.7)^{\mathrm{ab}}$ & $2.7(2.5-3.2)^{b c}$ \\
\hline LVIDs $_{\text {inc }}(\%)$ & $8.4(-0.4 \text { to } 30)^{\mathrm{a}}$ & $21(12-41)^{a}$ & $22(17-42)^{a b}$ & $43(25-58)^{b c}$ \\
\hline FS (\%) & $31(27-34)^{a}$ & $29(25-34)^{a}$ & $35(31-37)^{a b}$ & $37(31-41)^{b c}$ \\
\hline Catestatin (nmol/L) & $1.2(1.0-1.3)^{\mathrm{a}}$ & $1.1(1.0-1.2)^{\mathrm{a}}$ & $1.1(0.9-1.3)^{\mathrm{a}}$ & $1.1(0.9-1.2)^{\mathrm{a}}$ \\
\hline Vasostatin (nmol/L) & $0.23(0.15-0.33)^{\mathrm{a}}$ & $0.18(0.13-0.28)^{\mathrm{a}}$ & $0.22(0.14-0.44)^{\mathrm{a}}$ & $0.16(0.11-0.30)^{\mathrm{a}}$ \\
\hline NT-proBNP (pmol/L) & $549(375-800)^{\mathrm{a}}$ & $473(386-690)^{a}$ & $529(420-836)^{\mathrm{a}}$ & $3000(2129-3000)^{b}$ \\
\hline
\end{tabular}

Heart rate (HR), systolic blood pressure (SBP), diastolic blood pressure (DBP), echocardiographic data; ratio of left atrium to aortic root (LA/Ao), percentage increase in end-diastolic left ventricular internal dimension, $\left(\right.$ LVIDd $\left._{\text {inc }}\right)$ and end-systolic left ventricular internal dimension (LVIDs inc $)$, fractional shortening (FS), N-terminal-pro B-type natriuretic peptide (NT-proBNP). Values are reported as median and interquartile ranges (IQR). Within each row, values with the same superscript letter did not differ significantly $(P>0.008)$ 
in dogs in decompensated CHF compared to in dogs in compensated CHF (statistical comparison not performed due to low number of dogs) (Fig. 1). Catestatin concentration decreased with increasing left atrial size and left ventricular diastolic dimension both in all dogs $(\mathrm{n}=67)$ and when dogs in decompensated CHF were excluded $(\mathrm{n}=62)$; $\left(\mathrm{LA} / \mathrm{Ao}, \mathrm{R}^{2}=0.08, \mathrm{P}=0.019\right.$ in all dogs; $R^{2}=0.12, P=0.005$, decompensated excluded) and (LVIDd inc\%, $\mathrm{R}^{2}=0.09, \mathrm{P}=0.017$ in all dogs; $\mathrm{R}^{2}=0.10$, $\mathrm{P}=0.015$, decompensated excluded). Furthermore, catestatin concentration increased with increasing SBP both in all dogs $(n=67)$ and when dogs in decompensated CHF were excluded $(n=62)\left(R^{2}=0.08, P=0.022\right.$ in all dogs; $R^{2}=0.08, P=0.030$, decompensated excluded). Catestatin concentration also increased with increasing DBP in all dogs $\left(R^{2}=0.06, P=0.038\right)$, but did not reach significance for DBP when dogs in decompensated CHF were excluded $(P=0.052)$. For vasostatin, univariable regression analyses were non-significant for all included variables and the concentration did not differ between dogs with or without CHF. Catestatin and vasostatin concentrations did not differ between sexes.

\section{Discussion}

In this study of dogs with different severities of MMVD, the plasma catestatin concentration decreased with increasing left atrial and ventricular size, while it increased with increasing systolic and diastolic blood pressure.

The weak negative associations between catestatin concentration and indices of left atrial and ventricular size
$\left(\mathrm{R}^{2} \leq 0.09, \mathrm{P} \leq 0.019\right)$, were accompanied by a slightly numerically lower catestatin concentration in dogs with $\mathrm{CHF}$ compared to dogs without CHF. The small numerical difference was however not significant (Fig. 1).

Several studies have shown increased catestatin concentrations in people with acute myocardial infarction [15-18]. In contrast to the acute course in human myocardial infarction, the common canine cardiac disease MMVD is characterized by a slow but progressive disease development, usually over several years, eventually leading to development of CHF in some dogs [20, 23]. As expected, all indices of left atrial and ventricular size increased gradually with increasing disease severity and the severe MMVD group had significantly higher concentration of NT-proBNP compared to the other groups (Table 1), [39, 40]. The median NT-proBNP concentration of the severe group was approximately six times higher than the other three MMVD severity groups, indicating increased intra-cardiac pressure and volume overload in this group of dogs $[41,42]$. Ten of the 16 dogs in the severe group were in CHF and out of these, five were in decompensated CHF. Comparing dogs in decompensated $\mathrm{CHF}$ to dogs in compensated CHF, numerically higher catestatin concentration was found in dogs with decompensated CHF (Fig. 1). Due to the small number of dogs $(n=5)$ in each group, this could not be statistically evaluated, but is in agreement with previous findings of higher plasma norepinephrine concentrations in dogs in decompensated compared to compensated CHF, attributable to MMVD as well as DCM [26, 27]. Hence, the neurohormonal activation in our dogs in decompensated a

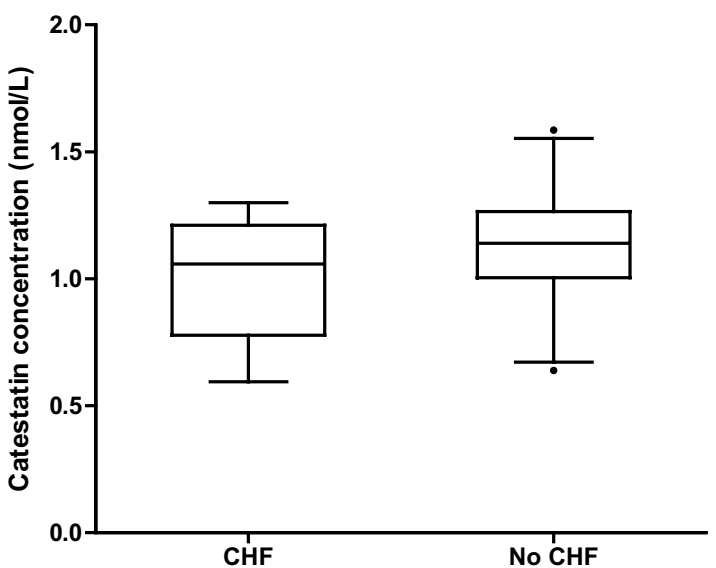

b

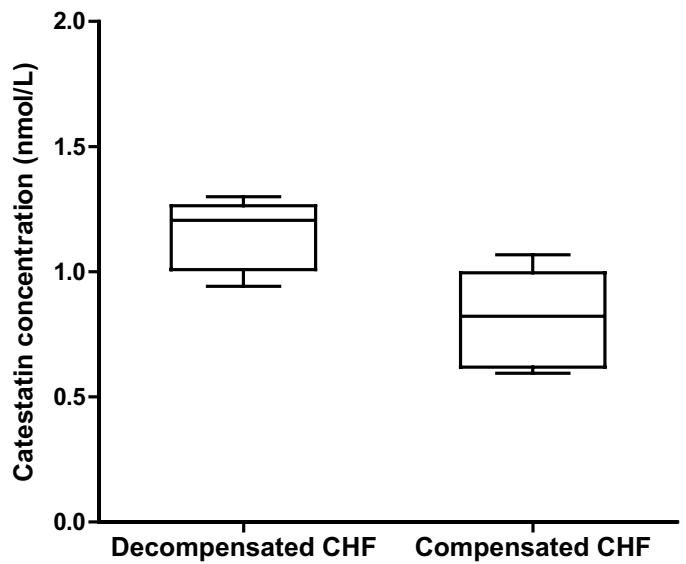

Fig. 1 Catestatin concentration in a dogs with $(n=10)$ and without $(n=56)$ congestive heart failure $(C H F)$ at the time of examination and $\mathbf{b}$ in dogs in decompensated $(n=5)$ versus compensated $(n=5)$ CHF at the time of examination. The top, bottom, and line within each box correspond to the 75th percentile (top quartile), the 25th percentile (bottom quartile), and the 50th percentile (median), respectively. The whiskers extend from the bottom 2.5 th percentile to the top 97.5 th percentile. Catestatin concentration did not differ between dogs with and without CHF (a), P $=0.10$. Due to the low number of dogs in each group in $\mathbf{b}$ statistical comparison could not be performed 
CHF could contribute to their catestatin concentration, but other sources of CgA likely also contribute. Studies suggest that CgA has a widespread distribution in a variety of polypeptide hormone producing human and bovine tissues $[3,43]$, and certain studies imply that the sympathochromaffin system may be the major source of circulating chromogranin A only in situations of highintensity sympathetic stimulation, such as in people with sepsis or cardiac arrest $[11,44]$. One study in people suggested that at basal to moderate stress levels, norepinephrine and epinephrine concentrations accounted for only $10-15 \%$ of the variance in plasma chromogranin A levels [44]. In our dogs, HR was higher in the severe group compared to the healthy and mild groups (Table 1), indicating increased sympathetic activation. However, the median HR in the severe group was only $120 \mathrm{bpm}$, which is not considered particularly high in dogs in a clinical situation [45]. Thus, potentially the relatively modest sympathetic activation in our dogs could explain the lack of difference between disease severity groups in catestatin and vasostatin concentrations.

Weak positive associations were found between catestatin concentration and systolic as well as diastolic blood pressure $\left(R^{2} \leq 0.08, P \leq 0.038\right)$. Both SBP and DBP were significantly lower in dogs with severe MMVD compared to the mild group (Table 1), which was an expected finding $[34,46,47]$. In human essential hypertension, CgA has been shown to be elevated while catestatin has been shown to be diminished $[48,49]$. This is in contrast to the positive associations between catestatin concentration and BP in this group of dogs. However, the BP values were within or at the upper end of normal limits for all MMVD severity groups [50].

The lower SBP and DBP in dogs with severe MMVD, compared to the mild group, was accompanied by increasing left atrial as well as left ventricular size with increasing disease severity (Table 1). During progression of MMVD, the regurgitant fraction over the mitral valve increases [51], and despite compensatory mechanisms, the left ventricular forward stroke volume might decrease, leading to a decrease in cardiac output and thereby potentially a decrease in SBP [34, 46, 47]. Interestingly, the negative associations between catestatin concentration and indices of left heart size as well as the positive association between catestatin concentration and SBP were maintained even when dogs in decompensated CHF were excluded. This might indicate a potential role of catestatin during progression of the disease. However, the associations found in the present study were weak, and this hypothesis would need to be tested in a larger study population.

The study has limitations. Samples had been thawed and re-frozen once before analysis, which could have affected results. However, because CgA has been shown stable to freezing and thawing [8], this should not have had major effect on the results. While it would have been interesting to measure full-length CgA, only the CgA fragments catestatin and vasostatin have been validated for canine plasma by the RIAs used in our laboratory [28], which precluded that analysis. At the time of sampling, 3 of the 67 dogs were treated with ACE-inhibitors, which might indirectly attenuate sympathetic activity. Excluding these 3 dogs from statistical analyses had no significant effect on the results. Finally, the study population was relatively small with proportionally few dogs in CHF.

\section{Conclusions}

In this population of dogs, the catestatin concentration showed weak negative associations with left atrial and ventricular size, both of which are known to increase with increasing severity of MMVD. Furthermore, the catestatin concentration showed weak positive associations with blood pressure.

\section{Abbreviations}

BNP: B-type natriuretic peptide; BP: Blood pressure; CgA: Chromogranin A; CHF: Congestive heart failure; DBP: Diastolic blood pressure; DCM: Dilated cardiomyopathy; FS: Fractional shortening; HR: Heart rate; IQR: Interquartile range; LA/Ao: Ratio of left atrium to aortic root; $L V I D d_{\text {inc: }}$ Percentage increase in end-diastolic left ventricular internal dimension; LVIDs inc: Percentage increase in end-systolic left ventricular internal dimension; MMVD: Myxomatous mitral valve disease; MR: Mitral regurgitation; NT-proBNP: N-terminalproBNP; RIA: Radioimmunoassay; SBP: Systolic blood pressure.

\section{Acknowledgements}

We thank all dog owners for allowing their dogs to participate in the study.

\section{Prior publication}

Data included in this article have previously been published in the Proceedings of the American College of Veterinary Medicine (ACVIM) Congress, Nashville, Tennessee, USA, June 4th-7th 2014.

\section{Authors' contributions}

$\mathrm{KH}, \mathrm{OH}, \mathrm{MS}, \mathrm{JH}$ and IL planned the study and IL, JH, KH collected the dog data. MS performed the laboratory analyses. KH performed the statistical analyses and all authors interpreted the findings. KH drafted the manuscript and all authors commented on the manuscript. All authors read and approved the final manuscript.

\section{Funding}

Open access funding provided by Swedish University of Agricultural Sciences. The study was funded by the Agria Research Foundation and Swedish Kennel Club Research Foundation. The funding body was not involved in study design, collection of samples, analyses, interpretation or writing of the manuscript.

\section{Availability of data and materials}

The dataset used and analyzed during the current study are available from the corresponding author on reasonable request.

\section{Ethics approval and consent to participate}

The study was approved by the Local Ethical Committee in Uppsala (Approval number (12/15), Sweden. Informed consent was obtained from each dog owner. 


\section{Consent for publication \\ Not applicable.}

\section{Competing interests}

The authors declare that they have no competing interests.

\begin{abstract}
Author details
${ }^{1}$ Department of Anatomy, Physiology and Biochemistry, Faculty of Veterinary Medicine and Animal Science, Swedish University of Agricultural Sciences, 750 07 Uppsala, Sweden. ${ }^{2}$ Department of Clinical Sciences, Faculty of Veterinary Medicine and Animal Science, Swedish University of Agricultural Sciences, 750 07 Uppsala, Sweden. ${ }^{3}$ Department of Medical Sciences, Faculty of Medicine, Uppsala University, 75185 Uppsala, Sweden. ${ }^{4}$ Anicura Albano Animal Hospital, Rinkebyvägen 21B, 18236 Danderyd, Sweden.
\end{abstract}

Received: 6 February 2020 Accepted: 30 July 2020

Published online: 05 August 2020

\section{References}

1. Blaschko H, Comline RS, Schneider FH, Silver M, Smith AD. Secretion of a chromaffin granule protein, chromogranin, from the adrenal gland after splanchnic stimulation. Nature. 1967;215:58-9.

2. Banks $P$, Helle K. The release of protein from the stimulated adrenal medulla. Biochem J. 1965;97:40C-1C. https://doi.org/10.1042/bj0970040c

3. O'Connor DT. Chromogranin: widespread immunoreactivity in polypeptide hormone producing tissues and in serum. Regul Pept. 1983;6:263-80.

4. Pieroni M, Corti A, Tota B, Curnis F, Angelone T, Colombo B, et al. Myocardial production of chromogranin $\mathrm{A}$ in human heart: a new regulatory peptide of cardiac function. Eur Heart J. 2007;28:1117-27. https://doi. org/10.1093/eurheartj/ehm022.

5. Helle KB, Metz-Boutigue MH, Cerra MC, Angelone T. Chromogranins: from discovery to current times. Pflügers Arch. 2018;470:143-54. https://doi. org/10.1007/s00424-017-2027-6.

6. Helle KB. The chromogranin A-derived peptides vasostatin-I and catestatin as regulatory peptides for cardiovascular functions. Cardiovasc Res. 2010;85:9-16. https://doi.org/10.1093/cvr/cvp266.

7. Hjemdahl P, Linde B. Influence of circulating NE and Epi on adipose tissue vascular resistance and lipolysis in humans. Am J Physiol. 1983:245:H447-52.

8. O'Connor DT, Pandlan MR, Carlton E, Cervenka JH, Hslao RJ. Rapid radioimmunoassay of circulating chromogranin A: in vitro stability, exploration of the neuroendocrine character of neoplasia, and assessment of the effects of organ failure. Clin Chem. 1989:35:1631-7.

9. O'Connor DT, Frigon RP. Chromogranin A, the major catecholamine storage vesicle soluble protein. Multiple size forms, subcellular storage, and regional distribution in chromaffin and nervous tissue elucidated by radioimmunoassay. J Biol Chem. 1984;259:3237-47.

10. Yanavitski M, Givertz MM. Novel biomarkers in acute heart failure. Curr Heart Fail Rep. 2011;8:206-11. https://doi.org/10.1007/s1189 7-011-0065-5.

11. Røsjø H, Nygard S, Kaukonen KM, Karlsson S, Stridsberg M, Ruokonen $E$, et al. Prognostic value of chromogranin A in severe sepsis: data from the FINNSEPSIS study. Intensive Care Med. 2012;38:820-9. https://doi. org/10.1007/s00134-012-2546-8

12. Ceconi C, Ferrari R, Bachetti T, Opasich C, Volterrani M, Colombo B, et al. Chromogranin A in heart failure; a novel neurohumoral factor and a predictor for mortality. Eur Heart J. 2002;23:967-74. https://doi.org/10.1053/ euhj.2001.2977.

13. Dieplinger B, Gegenhuber A, Struck J, Poelz W, Langsteger W, Haltmayer $\mathrm{M}$, et al. Chromogranin $\mathrm{A}$ and $\mathrm{C}$-terminal endothelin-1 precursor fragment add independent prognostic information to amino-terminal proBNP in patients with acute destabilized heart failure. Clin Chim Acta. 2009;400:91-6. https://doi.org/10.1016/j.cca.2008.10.012.

14. Estensen ME, Hognestad A, Syversen U, Squire I, Ng L, Kjekshus J, et al. Prognostic value of plasma chromogranin A levels in patients with complicated myocardial infarction. Am Heart J. 2006;152(927):e1-6. https ://doi.org/10.1016/j.ahj.2006.05.008.
15. Liu L, Ding W, Li R, Ye X, Zhao J, Jiang J, et al. Plasma levels and diagnostic value of catestatin in patients with heart failure. Peptides. 2013;46:20-5. https://doi.org/10.1016/j.peptides.2013.05.003.

16. Meng L, Wang J, Ding WH, Han P, Yang Y, Qi LT, et al. Plasma catestatin level in patients with acute myocardial infarction and its correlation with ventricular remodelling. Postgrad Med J. 2013;89:193-6. https://doi. org/10.1136/postgradmedj-2012-131060.

17. Zhu D, Xie H, Wang X, Liang Y, Yu H, Gao W. Correlation of plasma catestatin level and the prognosis of patients with acute myocardial infarction. PLoS ONE. 2015;10:e0122993. https://doi.org/10.1371/journal.pone.01229 93.

18. Borovac JA, Glavas D, Susilovic Grabovac Z, Supe Domic D, D'Amario D, Bozic J. Catestatin in acutely decompensated heart ailure patients: insights from the CATSTAT-HF study. J Clin Med. 2019. https://doi. org/10.3390/jcm8081132

19. Pan WQ, He YH, Su Q, Yang J, Fang YH, Ding FH, et al. Association of decreased serum vasostatin-2 level with ischemic chronic heart failure and with MACE in 3-year follow-up: vasostatin-2 prevents heart failure in myocardial infarction rats. Int J Cardiol. 2016;221:1-11. https://doi. org/10.1016/j.ijcard.2016.06.065.

20. Whitney JC. Observations on the effect of age on the severity of heart valve lesions in the dog. J Small Anim Pract. 1974;15:511-22.

21. Detweiler DK, Patterson DF. The prevalence and types of cardiovascular disease in dogs. Ann N Y Acad Sci. 1965;127:481-516. https://doi. org/10.1111/j.1749-6632.1965.tb49421.x

22. Egenvall A, Bonnett BN, Häggström J. Heart disease as a cause of death in insured Swedish dogs younger than 10 years of age. J Vet Intern Med. 2006;20:894-903. https://doi.org/10.1892/0891-6640(2006)20\%5b894 :hdaaco\% 5 d2.0.co;2.

23. Buchanan JW. Chronic valvular disease (endocardiosis) in dogs. Adv Vet Sci Comp Med. 1977:21:75-106.

24. Oyama MA. Neurohormonal activation in canine degenerative mitral valve disease: implications on pathophysiology and treatment. J Small Anim Pract. 2009;50(Suppl 1):3-11. https://doi.org/10.111 1/j.1748-5827.2009.00801.x.

25. Sisson DD. Neuroendocrine evaluation of cardiac disease. Vet Clin N Am Small Anim Pract. 2004;34:1105-26. https://doi.org/10.1016/j. cvsm.2004.05.005.

26. O'Sullivan ML, O'Grady MR, Minors SL. Plasma big endothelin-1, atrial natriuretic peptide, aldosterone, and norepinephrine concentrations in normal Doberman Pinschers and Doberman Pinschers with dilated cardiomyopathy. J Vet Intern Med. 2007:21:92-9.

27. Ware WA, Lund DD, Subieta AR, Schmid PG. Sympathetic activation in dogs with congestive heart failure caused by chronic mitral valve disease and dilated cardiomyopathy. J Am Vet Med Assoc. 1990;197:1475-81.

28. Stridsberg M, Pettersson A, Hagman R, Westin C, Höglund O. Chromogranins can be measured in samples from cats and dogs. BMC Res Notes. 2014;7:336. https://doi.org/10.1186/1756-0500-7-336.

29. Olsen LH, Martinussen T, Pedersen HD. Early echocardiographic predictors of myxomatous mitral valve disease in dachshunds. Vet Rec. 2003;152:293-7. https://doi.org/10.1136/vr.152.10.293.

30. Ljungvall I, Höglund K, Lilliehöök I, Oyama MA, Tidholm A, Tvedten H, et al. Serum serotonin concentration is associated with severity of myxomatous mitral valve disease in dogs. J Vet Intern Med. 2013;27:1105-12. https://doi.org/10.1111/jvim.12137.

31. Belanger MC. Echocardiography. In: Ettinger SJ, Feldman EC, editors. Textbook of veterinary internal medicine. 6th ed. St Louis: Elsevier Saunders; 2005. p. 311-26.

32. Hansson $\mathrm{K}$, Häggström J, Kvart C, Lord P. Left atrial to aortic root indices using two-dimensional and M-mode echocardiography in cavalier King Charles spaniels with and without left atrial enlargement. Vet Radiol Ultrasound. 2002:43:568-75.

33. Pedersen HD, Kristensen B, Norby B, Lorentzen KA. Echocardiographic study of mitral valve prolapse in Dachshunds. Zentralbl Veterinarmed A 1996:43:103-10.

34. Ljungvall I, Höglund K, Carnabuci C, Tidholm A, Häggström J. Assessment of global and regional left ventricular volume and shape by real-time 3-dimensional echocardiography in dogs with myxomatous mitral valve disease. J Vet Intern Med. 2011;25:1036-43. https://doi. org/10.1111/j.1939-1676.2011.0774.x. 
35. Reimann MJ, Moller JE, Haggstrom J, Markussen B, Holen AE, FalkT, et al. $R$ - $R$ interval variations influence the degree of mitral regurgitation in dogs with myxomatous mitral valve disease. Vet J. 2014;199:348-54. https ://doi.org/10.1016/j.tvjl.2014.01.001.

36. Cornell CC, Kittleson MD, Della Torre P, Haggstrom J, Lombard CW, Pedersen $\mathrm{HD}$, et al. Allometric scaling of $\mathrm{M}$-mode cardiac measurements in normal adult dogs. J Vet Intern Med. 2004;18:311-21.

37. Stridsberg M, Angeletti $\mathrm{RH}$, Helle KB. Characterisation of N-terminal chromogranin $A$ and chromogranin B in mammals by region-specific radioimmunoassays and chromatographic separation methods. J Endocrinol. 2000;165:703-14. https://doi.org/10.1677/joe.0.1650703.

38. Stridsberg M, Eriksson B, Oberg K, Janson ET. A panel of 11 region-specific radioimmunoassays for measurements of human chromogranin $A$. Regul Pept. 2004;117:219-27. https://doi.org/10.1016/j.regpep.2003.10.023.

39. Tarnow I, Olsen LH, Kvart C, Höglund K, Moesgaard SG, Kamstrup TS, et al. Predictive value of natriuretic peptides in dogs with mitral valve disease. Vet J. 2009;180:195-201. https://doi.org/10.1016/j.tvjl.2007.12.026.

40. Hezzell MJ, Boswood A, Chang YM, Moonarmart W, Souttar K, Elliott J. The combined prognostic potential of serum high-sensitivity cardiac troponin I and N-terminal pro-B-type natriuretic peptide concentrations in dogs with degenerative mitral valve disease. J Vet Intern Med. 2012;26:302-11. https://doi.org/10.1111/j.1939-1676.2012.00894.x.

41. van Wamel JE, Ruwhof C, van der Valk-Kokshoorn EJ, Schrier PI, van der Laarse A. Rapid gene transcription induced by stretch in cardiac myocytes and fibroblasts and their paracrine influence on stationary myocytes and fibroblasts. Pflügers Arch. 2000;439:781-8. https://doi. org/10.1007/s004240000253.

42. Mantymaa P, Vuolteenaho O, Marttila M, Ruskoaho H. Atrial stretch induces rapid increase in brain natriuretic peptide but not in atrial natriuretic peptide gene expression in vitro. Endocrinology. 1993;133:1470-3.

43. O'Connor DT, Burton D, Deftos LJ. Immunoreactive human chromogranin A in diverse polypeptide hormone producing human tumors and normal endocrine tissues. J Clin Endocrinol Metab. 1983;57:1084-6. https://doi. org/10.1210/jcem-57-5-1084.
44. Cryer PE, Wortsman J, Shah SD, Nowak RM, Deftos LJ. Plasma chromogranin $A$ as a marker of sympathochromaffin activity in humans. Am J Physiol. 1991;260:E243-6. https://doi.org/10.1152/ajpendo.1991.260.2.E243.

45. Hamlin RL, Olsen I, Smith CR, Boggs S. Clinical relevancy of heart rate in the dog. J Am Vet Med Assoc. 1967;151:60-3.

46. Petit AM, Gouni V, Tissier R, Trehiou-Sechi E, Misbach C, Pouchelon JL, et al. Systolic arterial blood pressure in small-breed dogs with degenerative mitral valve disease: a prospective study of 103 cases (2007-2012). Vet J. 2013;197:830-5. https://doi.org/10.1016/j.tvjl.2013.05.040.

47. Boswood A, Häggström J, Gordon SG, Wess G, Stepien RL, Oyama MA, et al. Effect of pimobendan in dogs with preclinical myxomatous mitral valve disease and cardiomegaly: the EPIC Study — a randomized clinical trial. J Vet Intern Med. 2016;30:1765-79. https://doi.org/10.1111/ jvim. 14586.

48. Zhu D, Wang F, Yu H, Mi L, Gao W. Catestatin is useful in detecting patients with stage B heart failure. Biomarkers. 2011;16:691-7. https://doi. org/10.3109/1354750X.2011.629058.

49. Mahata SK, Kiranmayi M, Mahapatra NR. Catestatin: a master regulator of cardiovascular functions. Curr Med Chem. 2018;25:1352-74. https://doi. org/10.2174/0929867324666170425100416.

50. Acierno MJ, Brown S, Coleman AE, Jepson RE, Papich M, Stepien RL, et al. ACVIM consensus statement: guidelines for the identification, evaluation, and management of systemic hypertension in dogs and cats. J Vet Intern Med. 2018;32:1803-22. https://doi.org/10.1111/jvim.15331.

51. Beardow AW, Buchanan JW. Chronic mitral valve disease in cavalier King Charles spaniels: 95 cases (1987-1991). J Am Vet Med Assoc. 1993;203:1023-9.

\section{Publisher's Note}

Springer Nature remains neutral with regard to jurisdictional claims in published maps and institutional affiliations.
Ready to submit your research? Choose BMC and benefit from:

- fast, convenient online submission

- thorough peer review by experienced researchers in your field

- rapid publication on acceptance

- support for research data, including large and complex data types

- gold Open Access which fosters wider collaboration and increased citations

- maximum visibility for your research: over $100 \mathrm{M}$ website views per year

At BMC, research is always in progress.

Learn more biomedcentral.com/submissions 